\title{
Political and Philosophical Ideas of Socio-Political Development of Russia: Opportunities in Modern Conditions
}

\author{
M. V. Yakovlev ${ }^{1}$
}

${ }^{1}$ Lomonosov Moscow State University, 27 bldg. 4 Lomonosovsky Prospekt, Moscow 119991, Russian Federation

DOI: $10.18255 / 2412-6519-2021-2-158-165$

Research Article Full text in Russian

The article draws attention to the risks associated with the loss of national research traditions in political theory. It is shown that non-creative borrowing and imitative reproduction of foreign concepts and theories does not contribute to the scientific rise, especially if the Russian heritage and scientific schools are pushed aside and forgotten. To attract the attention of academic circles to the existing potential of Russian socio-political thought and discuss opportunities for further development, the article analyzes and compares the concepts of "Autocracy of the people", "Holy Russia", "Moscow - the Third Rome", and "Spiritual Vertical". Their philosophical and political significance for the development of the Russian state in modern conditions is determined. Conclusions are drawn that due to the alienation of citizens, especially young people, from the national intellectual tradition (together with economic and political reasons), emigration moods, spiritual decline, and pessimism are expanding in Russian society.

The problem could be a funded study, support and promotion oriented to the spiritual development of the adherents of the concepts of "Holy Russia" and the likes, which have a long history, formed in the domestic tradition, belong to the history of the first and the second Rome have religious and philosophical and political justification provide the basis for social and national consolidation of many peoples of the Russian state.

Keywords: "Holy Russia”; "Moscow - Third Rome”; national features of politics; political ideology; Russia; socio-political development; "Spiritual vertical"

INFORMATION ABOUT THE AUTHORS

Yakovlev, Maxim V.

E-mail: maxvuz@mail.ru ORCID 0000-0002-0127-5642

Doc. Sc. (Psychology), Professor

For citation: Yakovlev M. V. Political and Philosophical Ideas of Socio-Political Development of Russia: Opportunities in Modern Conditions // Social'nye i gumanitarnye znanija. 2021. Vol. 7, No 2. P. 158-165. (in Russ.) 


\title{
Политико-философские идеи общественно- политического развития России: возможности в современных условиях
}

\author{
М. В. Яковлев ${ }^{1}$
}

${ }^{1}$ Московский государственный университет имени М. В. Ломоносова, Ломоносовский проспект, д. 27, корп. 4, Москва, 119991, Российская Федерация

DOI: $10.18255 / 2412-6519-2021-2-158-165$

УДК 32.019 .5

Научная статья

Полный текст на русском языке

В статье обращается внимание на риски, связанные с утратой национальных исследовательских традиций в политической теории. Показываются неблагоприятные последствия нетворческого заимствования и подражательного воспроизводства зарубежных концепций и подходов, особенно если при этом в сторону отодвигаются и подвергаются забвению российские философско-политические идеи и научные школы.

Для привлечения внимания академических кругов к потенциалу отечественной общественно-политической мысли и обсуждения ее возможностей в статье аналитически рассматриваются и сопоставляются концепты «Духовная вертикаль», «Москва - Третий Рим», «Самодержавие народа», «Святая Русь». Определяется их значение для научного подъема и для эволюции российского государства в современных условиях.

Делаются выводы о том, что по причине отчуждения граждан, прежде всего молодежи, от отечественной интеллектуальной традиции (вкупе с причинами экономического и политического характера) в российском обществе расширяются эмиграционные настроения, духовный упадок, пессимизм, что уже в среднесрочной перспективе может привести к крушению суверенной российской государственности и культуры.

Одним из решений проблемы может стать фундированное исследование, развитие и продвижение ориентирующимися на духовное развитие единомышленниками созданных в России концепций, которые имеют многовековую историю, оформились в отечественную традицию, относятся к истории и первого, и второго Рима, имеют развернутое философско-политическое обоснование, служат базой для общественной и национальной консолидации многих народов России.

Ключевые слова: «духовная вертикаль»; «Москва - Третий Рим»; национальные особенности политики; политическая идеология; Россия; «Святая Русь»; социально-политическое развитие

ИНФОРМАЦИЯ ОБ АВТОРАХ

Яковлев, Максим Владимирович

E-mail: maxvuz@mail.ru

ORCID 0000-0002-0127-5642

Доктор политических наук, профессор кафедры философии политики и права философского факультета

Для цитирования: Яковлев М. В. Политико-философские идеи общественно-политического развития России: возможности в современных условиях // Социальные и гуманитарные знания. 2021. Том 7, № 2. C. 158-165.

(C) Яковлев М. В., 2021

Статья открытого доступа под лицензией СС BY (https://creativecommons.org/licenses/by/4.0/) 
Обсуждения последних лет, ведущиеся в сообществе российских ученых и преподавателей, демонстрируют утверждение и поддержку преимущественно зарубежных концептов и понятий в области политической теории. На первый взгляд это может показаться результатом включения в доминирующую парадигму, а также частью устремления на воспроизводство тех моделей (образа жизни, научных методологий и т.д.), которые представляются наиболее успешными и передовыми. Аналогичные тенденции, развертывающиеся в более общем контексте глобализации, наблюдаются во многих странах. Однако более глубокое и критическое рассмотрение позволяет увидеть ряд значительных проблем.

Во-первых, в нашем обществе страсть перенимать что-либо (подчас слепо, в искаженном виде) давно оформилась в черту национального характера (чем вряд ли следует гордиться). Еще Стендаль писал о том, что «русские старательно копируют французские нравы, только отставая лет на пятьдесят» [1, с. 37].

Во-вторых, стремление влиться в торжественное шествие мирового научного авангарда под лозунгами инноваций и прогресса заслуживает всяческого поощрения. Разумеется, делать это лучше всего степенно, с чувством собственного достоинства и накопленным в результате кропотливого исследовательского труда весомым вкладом, который обеспечит признание заслуг и почетное место в рядах авторитетных ученых. Суетливая попытка пристроиться к процессии сбоку, под прикрытием чужих имен и достижений, вряд ли приведет к чему-то хорошему - в лучшем случае самозванца мягко отстранят на обочину. В худшем незадачливый подражатель, легкомысленно отказавшийся от опоры на собственную интеллектуальную традицию, вряд ли устоит в ходе общего движения вперед, пошатнется, толкнет других или вовсе собьет их с ног. И в начавшейся сумятице будут повержены наземь эмблемы инноваций и прогресса, весь парад мировой науки остановится.

B-третьих, копирование чужих стандартов и понятий, пусть даже самое старательное и дисциплинированное, вкупе с игнорированием отечественных достижений, может оказаться причиной, как выразился бы М. Вебер, ненамеренных последствий, которые угрожают серьезными опасностями и потерями.

Автор этих строк уже указывал, например, на то, что массовое увлечение теориями либеральной демократии повлекло за собой почти полное забвение истории российской демократической практики (от вечевых традиций до представительства трудовых коллективов на советских предприятиях, опыт которых, в частности, был учтен в партиципаторной модели К. Макферсона [2]) и идей о народовластии, об общем благе, об общественном идеале, сформулированных русскими философами политики (И.А. Ильин, П.И. Новгородцев, Ф.А.Степун, Б. Н. Чичерин и др. [3; 4; 5; 6; 7, с. 4]). Полагаю, что найдутся скептики, которые выскажут большие сомнения в познавательном потенциале указанных философскополитических идей применительно к сегодняшним реалиям и заявят об их упадке. Здесь можно привести контрдоводы, однако для экономии времени и мышления сразу прибегну к аргументу, к которому вряд ли можно отнестись легкомысленно и с недоверием.

Речь идет о том, что вдохновленная западными концептами и образами российская молодежь, особенно наиболее талантливая и перспективная ее часть, же- 
лает уехать из России. По данным исследования ВЦИОМ, проведенного в августе 2018 г., 31 \% молодых россиян в возрасте от 18 до 24 лет хотел бы переехать в другую страну на постоянное место жительства [8].

В январе 2019 г. специалисты Левада-центра в ходе опроса сделали вывод о том, что $41 \%$ россиян в возрасте от 18 до 24 лет хотел бы переехать жить за границу [9].

Конечно, причины этих настроений кроются и в экономическом положении, и в политическом состоянии нашего государства. Но хотелось бы отвлечься от установок марксистской теории, а также от объяснений, базирующихся на связи между социально-экономическим развитием и общественным устройством (тезисы А. Пшеворского, У. Ростоу, С. Липсета и др. [10; 11; 12]), и обратить внимание на то, что не только способ производства и/или рост благосостояния, но и сами идеи также имеют большую силу в массовом сознании, программируют развитие народов, меняют их историю и будущее, что очень хорошо показал упоминавшийся выше М. Вебер.

Можно утверждать, что во многом именно ввиду отчуждения от объединяющих и вселяющих энтузиазм национальных идей, придающих подлинную ценность и значение Отечеству, российская молодежь, сегодня обучаемая на основе западных подходов, находящаяся под влиянием западных ценностей, не знающая отечественных достижений или имеющая о них искаженное представление, не хочет созидать в России и намеревается устроить свою жизнь в других странах.

Среди таких идей, пожалуй, одно из наиболее заметных мест занимает концепт «Святая Русь», который появился в отечественной литературе не позднее середины XVIв. Согласно А. В.Соловьеву, впервые это понятие встречается у А. М. Курбского [13, с. 234-269]. Профессор Йельского университета П. Бушкович нашел его в одном из сочинений Максима Грека [14, с. 36].

Позднее, в XVII-XVIII вв., широкую известность получило фольклорное истолкование «Святой Руси» в таких произведениях, как «Поэтическая повесть об Азовском осадном сидении донских казаков» Ф. И. Порошина, сборнике русских былин Кирши Данилова и др. В XIX в. словосочетание довольно часто употребляется в среде русских интеллектуалов: о нем говорят Ф. Н. Глинка, П. А. Вяземский и др. [15, с. 15$]$.

В народном восприятии значение понятия «Святая Русь» изначально связано с Православной церковью и православной верой. На это указывает, например, Г. П. Федотов, исходя из стихов о Егории Храбром, в которых герой сражается в Палестине за Святую Русь, а его матушка плачет в Иерусалиме - в центре Святой Руси [16]. Причем жители «Святой Руси» - это не только и не столько русские, это многие люди и народы, исповедующие православие (татары, чуваши, удмурты, якуты, осетины, русские и др.).

Аналогичная картина наблюдалась и во Второй Римской империи, где ромеями именовались не только греки, но и все жители: православные, подданные православного императора, носители христианской цивилизации.

В сущности, тот же тезис воспроизводится и в концепции «Москва - Третий Рим», где утверждается представление о Руси, народ которой сохранил приверженность истинной вере - православию, как о третьем Риме, т. е. православной империи, православном мире (при этом Москва ассоциируется с Иерусалимом). 
Интересно заметить, как здесь сопоставляются и передаются созвучие и смысл слов «Рим» и «мир»: Рим - это тот мир, который исповедует православие, а Русь - это и есть православный Рим-мир.

Очевидно, что теория эта по сути своей имперская. Однако здесь необходимо сделать важную оговорку. Она не направлена на обоснование амбиций и претензий России на создание мировой империи, она исходит из посылки о том, что христианский мир - это обязательно империя, и в настоящее время волей высшей силы центром этой империи стала Москва - Третий Рим как оплот православного христианства.

В этой концептуальной призме «Святая Русь» предстает метафизической и метаисторической идеей православного мира - империи Рима, которая существует вечно (при этом ее географические центры и материальные формы могут меняться).

Впоследствии рассмотрение понятия «Святая Русь» продолжили С. С. Аверинцев, А. А. Горский, И. Н. Данилевский, Ф. Кэмпфер, Б. А. Рыбаков и др. Фундированное обоснование оно получило в рамках исследовательского проекта «Confessiones et nationes».

Суть феномена «Святой Руси» академик В. Н. Топоров определил как некую квинтэссенцию всей отечественной истории, включающую в себя великие духовные ценности: святых людей, святых текстов, святых икон; как «святость вопреки всему, признание ее высшей целью, сознание неразрывной - на глубине - связи с нею и веры во всеобщее распространение в будущем» [17, с. 11].

Можно сделать вывод о том, что понятие «Святая Русь» не связано ни с этничностью, ни с нацией, оно обозначает устремленность к святости и духовности, которая на протяжении многих веков поддерживается в России (в то время как страны Запада ориентируются, в первую очередь, на извлечение прибыли и материальной выгоды).

Подобная трактовка концепта «Святая Русь» может стать одним из оснований деятельности России, целью и смыслом ее существования в мировом сообществе. Она коренится в многовековой традиции, восходящей к истории и первого, и второго Рима, имеет и религиозное, и философское обоснование, служит рамкой для объединения многих народов, на опыте Российского государства показала свою действенность и жизнеспособность.

На эту тему Ф. М. Достоевский писал: «Я говорю про неустанную жажду в народе русском, всегда в нём присущую, великого, всеобщего, всенародного, всебратского единения во имя Христово...

Не в коммунизме, не в механических формах заключается социализм народа русского: он верит, что спасается лишь в конце концов всесветным единением во имя Христово. Вот наш русский социализм...

Кто не понимает в народе нашем его православия и окончательных целей его, тот никогда не поймет и русского...» $[18$, с. 19].

В свою очередь, немецкий мыслитель и историк В. Шубарт отмечает: «Русский не является человеком массы, он высоко ценит свободу человеческой личности... Идеалом личности на Западе является сверхчеловек, в России - всечеловек. Сверхчеловек стремится ввысь из жажды власти, всечеловек идёт вширь из чувства любви» [19, с. 79]. В. Шубарт склонен считать соборность русских формой демократии: «Если он (русский - прим. авт.) смотрит на ближнего своего, он видит 
в нем не врага, а брата. Он верит в естественную доброту ближнего вплоть до доказательства противного... Чувство братства делает русскому жизнь много легче и выносимее, чем европейцу с его инстинктом борьбы, грабительства и конкуренции... Сколь братским является обычай называть друг друга не по титулам и званиям, а по имени и отчеству. Это признак подлинного и внутреннего демократизма» [Там же. С. 76].

С учетом положений Ф. М. Достоевского, В. Шубарта и других мыслителей в настоящее время концепт «Святая Русь» может рассматриваться как основание для нового союза народов и стран, как ориентир для (вос)создания вселенской христианского государства.

Конечно, с одной стороны, эти идеи довольно далеки от светского мышления, во многом навязанного. С другой стороны, эти идеи и сейчас имеют немало сторонников во многих частях мира, которые могут объяснять и распространять свои взгляды и привлекать новых последователей.

Созвучен этим положениям и тезис А. С. Панарина о «духовной вертикали», под которой понимается строительство на евразийском континенте новой геополитической линии Север-Юг, олицетворяемой союзом Индии и России. Духовной доминантой этого объединения провозглашается «нравственно-религиозный дух солидарности и сострадательности» [20, с. 229]. А. С. Панарин полагал, что общая духовная ориентация открывает совершенно новые перспективы для такого союза.

Еще один очень интересный концепт из корпуса отечественной философско-политической мысли - это «самодержавие народа» («народное самодержавие»). Он был сформулирован идеологами «Народной воли» и получил известность уже в 1879 г. [21, с. 168]. Один из его авторов, Л. А. Тихомиров, рассматривал этот концепт как одну из двух главных основ миросозерцания народа (наряду со всеобщим правом на землю) [22, с. 22].

Один из наиболее известных разработчиков этого понятия Я. М. Магазинер указывал, что «действительное самодержавие какого-нибудь класса мирится лишь с фикцией самодержавия всего народа, поскольку эта фикция необходима для создания или упрочения его господства» [23, с. 111].

Концепт «самодержавие народа» оказался столь емким, актуальным и многоплановым, что в дальнейшем его активно использовали Г. В. Плеханов, В. И. Ленин, И. В. Сталин [24, с. 122].

В этом понятии содержались и момент противостояния с «самодержавием царя», и самобытность России. Кроме того, оно было предельно понятно для самой широкой аудитории.

Итак, именно сильная объединяющая идея, основанная на традициях христианства, представляющая собой альтернативу и секулярному капитализму, и всемирному халифату, может вдохновить молодежь и другие группы граждан на то, чтобы остаться на Родине, достичь личного успеха, принести пользу обществу, внести весомый вклад в научное развитие. Одной политико-философской идеи, какой бы мощной она ни была, явно недостаточно.

Ясно, что еще одним необходимым условием является отыскание и наделение полномочиями таких людей, которые составили бы правящий класс, отличающийся высокой моральной ответственностью и, безусловно, ориентирующийся на государственное и общественное развитие. Кроме того, необходима поддержка 
авторитетных российских исследователей, которые знают и совершенствуют отечественную интеллектуальную традицию и сочетают ее с новейшими зарубежными достижениями. И здесь в качестве примера можно привести работу научной школы Ярославского государственного университета имени П.Г.Демидова, в частности, организацию и проведение Всероссийской научно-практической конференции «Современное российское общество: социально-политические тренды и вызовы», которая стала солидной площадкой для очень плодотворной дискуссии в декабре 2020 г.

Действенной стратегией, нацеленной на то, чтобы занять почетное место в мировой политической науке, представляется не простой повтор заимствованных категорий и теорий, а план сохранения и преумножения отечественного потенциала и направление усилий на самостоятельное создание того нового, что может стать ценным вкладом в развитие мировой социально-политической мысли, что может усовершенствовать устройство нашей страны и других государств, конечно, в совокупности с достижениями зарубежных коллег.

При совмещении всех указанных обстоятельств наиболее вероятны и начало нового этапа в развитии российской нации, и занятие ее представителями достойного места в первом ряду мировой политической теории и науки.

\section{Ссылки / References}

1. Стендаль. Красное и черное // Собрание сочинений в 12 т. Т. 2. М.: Правда, 1978. $480 \mathrm{c}$.

2. Макферсон К. Жизнь и времена либеральной демократии. М.: ГУ ВШЭ, 2011. 174 с.

3. Ильин И. А. Понятия права и силы; Общее учение о праве и государстве; О сущности правосознания; О монархии и республике; Из лекций «Понятия монархии и республики» // Собрание сочинений: в 10 т. Т. 4. М.: Русская книга, 1994. 624 с.

4. Новгородцев П. И. Об общественном идеале. М.: Пресса, 1991. 640 с.

5. Степун Ф. А. Идея России и формы ее раскрытия // Новый Град. 1934. № 8. С. 15-27.

6. Чичерин Б. Н. О народном представительстве. М.: Тип. т-ва И. Д. Сытина, 1899. 810 с.

7. Яковлев М. В. Идеи демократии в политической мысли стран СНГ. Уфа: Альфареклама, 2016. 352 с.

8. Эмиграционные настроения россиян-2018 // ВЦИОМ: официальный сайт. 2018. URL: https://wciom.ru/index.php?id=236\&uid=9187 (дата обращения: 05.01.2021).

9. Эмиграционные настроения // Левада-центр: официальный сайт. 2019. URL: https://www.levada.ru/2019/02/04/emigratsionnye-nastroeniya-3/ (дата обращения: 05.01.2021).

10. Democracy and Development: Political Institutions and Well-Being in the World, 19501990 / A. Przeworski, M. Alvarez, J. Cheibub, F. Limongi. Cambridge, 2000. 340 p.

11. Ростоу У.У. Политика и стадии роста. М.: Прогресс, 1973. 208 с.

12. Lipset S. M. Some Social Requisites of Democracy: Economic Development and Political Legitimacy // American Political Science Review. 1959. № 53 (March). P. 69-105. 
13. Соловьев А. В. Святая Русь. Очерк развития религиозно-общественной идеи // Русская государственность в трудах историков зарубежья. М.: Вече, 2012. С. $234-$ 269.

14. Бушкович П. Православная церковь и русское национальное самосознание XVIXVII веков // Конфессия, империя, нация. Религия и проблема разнообразия в истории постсоветского пространства. М.: Новое издательство, 2012. С. 36-55.

15. Дмитриев М. В. Проблематика исследовательского проекта «Confessiones et nations». Конфессиональные традиции и протонациональные дискурсы в истории Европы // Религиозные и этнические традиции в формировании национальных идентичностей в Европе. Средние века - Новое время: сборник статей. М.: Индрик, 2008. C. $15-45$.

16. Федотов Г. П. Стихи духовные. Русская народная вера по духовным стихам. М.: Гнозис, 1991. 192 с.

17. Топоров В. Н. Святость и святые // Сочинения в 2 т. Т. 1. Три века христианства на Руси. М.: Языки русской культуры, 1998. 874 с.

18. Достоевский Ф. М. Полное собрание сочинений в 30 т. Т. 27. Л.: Наука, 1980. 463 с.

19. Шубарт В. Европа и душа Востока. Франкфурт-на-Майне: Посев, 1947. 123 с.

20. Панарин А. С. Глобальное политическое прогнозирование. М.: Алгоритм, 2002. 352 с.

21. Литература социально-революционной партии «Народной Воли». СПб.: Типография Партии Социалистов-Революционеров, 1905. 978 с.

22. Тихомиров Л. А. Чего нам ждать от революции? СПб.: Издание группы типографщиков Народной Воли, 1885. 29 с.

23. Магазинер Я. М. Самодержавие народа. Опыт социально-политической конструкции суверенитета. СПб.: Издание Н. Глаголева, 1907. 150 с.

24. Никандров А. В. Концепт «самодержавие народа» в политической риторике большевиков и народнические истоки большевизма // Вопросы философии. 2020. Т. № 10. С. 122-133. 